\title{
Effects of feeding and cholecystokinin-octapeptide (CCK-8) on the somatotropic axis of goats around weaning
}

\author{
Y. Kobayashi1 ${ }^{1,3}$, M. Onodera ${ }^{1}$, M. Yoshida ${ }^{1}$, P. Guilloteau ${ }^{2}$, K. Katoh ${ }^{1}$ \\ and Y. Obara ${ }^{1}$
}

\author{
${ }^{1}$ Department of Animal Physiology, Graduate School of Agricultural Science, Tohoku University \\ Amamiyamachi, Sendai 981-8555, Japan \\ ${ }^{2} I N R A-U M R V P$, Domaine de la Prise \\ 35590 Saint Gilles, France
}

\begin{abstract}
Post-prandial plasma GH concentrations significantly increased prior to weaning but did not change or decrease after weaning in goats. We hypothesized that this phenomenon was induced by changes in the digestive function or in gastrointestinal hormone secretion at weaning. We therefore gave intravenous administrations of CCK-8 in order to establish whether or not it stimulated GH secretion. The administration in pre-weaned animals increased the GH level, but not ghrelin levels, which were significantly greater than in post-weaned animals. These results suggest that the regulation of somatotropic axis after feeding may be stimulated by peripherally secreted CCK.
\end{abstract}

KEY WORDS: weaning, feeding, growth hormone, cholecystokinin, ghrelin

\section{INTRODUCTION}

Ruminants, prior to weaning, digest milk and absorb nutrients from the intestinal epithelium, but after weaning ruminants digest forages by microbial fermentation and absorb volatile fatty acid (VFA) from the rumen. This means that the digestive function, nutrient metabolism and hormone secretion change around weaning.

Cholecystokinin (CCK) release was stimulated by feeding in pre-weaning calves, but it was suppressed after weaning (Toullec et al., 1992). CCK has a number of biological roles at central and peripheral sites: for instance, inhibition of food intake (Gibbs et al., 1973), gastric emptying and intestinal motility (Moran

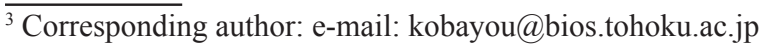


et al., 1994). Furthermore, it has been reported that i.p. CCK injection stimulates ghrelin secretion in rats (Murakami et al., 2002).

Ghrelin, a 28-amino acid peptide that is mainly secreted from the stomach, has recently been isolated as an endogenous ligand for the growth hormone secretagogue receptor (GHS-R) (Kojima et al., 1999). Ghrelin potently stimulates $\mathrm{GH}$ release when intravenously injected, suggesting that peripherally secreted ghrelin could regulate the somatotropic axis.

From these reports, we hypothesized that in ruminants peripherally secreted CCK would act not only as a gastrointestinal signaling factor but also as a regulator for the somatotropic axis via ghrelin. In the present study, we measured the plasma levels of GH, ghrelin, insulin and leptin after feeding, and assessed effects of CCK administration on hormonal traits in pre-weaning and post-weaning goats.

\section{MATERIAL AND METHODS}

\section{Animals and feeding}

Six and five Siba-goats, aged 4 and 13-w-old, respectively, were used. Animals were twice daily given milk replacer $(200 \mathrm{ml})$ at 10.00 and 16.00 until 4-w-old. From 4 to 7 weeks old, animals were given calf starter and lucerne hay cubes $a d$ libitum for the period of weaning. After 7-w-old, lucerne hay cubes were given ad libitum. Animals had free access to water and mineral salts throughout.

\section{Blood sampling schedule and sample preparation}

Animals were fitted with a catheter in the jugular vein $2 \mathrm{~h}$ before the experiment. trisodium citrate dihydrate (3\%) was used to prevent blood coagulation. Blood sampling was carried out from a.m. 9.30 to p.m. 1.00 at 15 min intervals. Feeding or CCK administration ( $150 \mathrm{pmol} / \mathrm{kg}$ ) was conducted just after the third sampling. Samples were immediately removed into heparinized $(10 \mathrm{IU} / \mathrm{ml}$ of blood) polypropylene tubes and centrifuged for $15 \mathrm{~min}$, and then plasma was stored at $-30^{\circ} \mathrm{C}$ until assayed, except for the ghrelin analyses.

\section{Preparation of sample for ghrelin assay}

Collected blood samples were immediately removed into heparinized polypropylene tubes with aprotinin $(10 \mathrm{KIU} / \mathrm{ml}$ of blood), and centrifuged for $15 \mathrm{~min}$, and then plasma was mixed with an equal amount of $1 \mathrm{~N}$ acetic acid buffer. Mixture was stored at $-30^{\circ} \mathrm{C}$ until extraction.

\section{Ghrelin extraction and assay}

Ghrelin in the mixture was extracted by acetone. The supernatant was evaporated after centrifugation, and the residue resuspended in assay buffer was used for the RIA. 


\section{Calculation and statistics}

From the change in the plasma concentrations of GH, leptin, ghrelin, insulin and CCK, the area under the curve (AUC) and incremental area of these hormones were calculated. Data were analysed by paired t-test and Duncan's test.

\section{RESULTS}

\section{Plasma levels after feeding}

In 4-w-old animals, plasma GH levels increased after feeding and remained at a higher level for 90 min after feeding, but there was no significant change in 13w-old animals. GH AUC and incremental area for 4-w-old animals were greater than those for 13-w-old animals. Ghrelin levels did not change significantly after

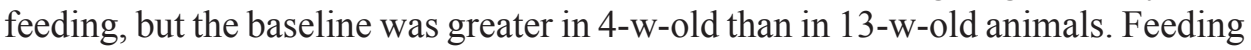
did not change the level of leptin.

\section{Plasma hormone levels after CCK-8 administration}

Although the basal GH level of 4-w-old animals was similar to the 13-w-old animals, a significant increase in 4-w-old animals was found 15 min after CCK administration. Incremental area for $\mathrm{GH}$ in 4-w-old animals was greater than that for 13-w-old animals, but there was no difference in AUC between 4- and 13-wold animals. No significant change was found in plasma insulin levels after CCK administration. The plasma level, AUC and incremental area of leptin did not change significantly. Plasma ghrelin levels in 4 -w-old animals were greater than that of 13-w-old animals. In 13-w-old animals, plasma ghrelin levels gradually increased after CCK administration. AUC for Ghrelin in 4-w-old animals was greater than in 13-w-old animals, although the incremental area in 4-w-old animals was lower than in 13-w-old animals.

\section{DISCUSSION}

The present finding indicates that plasma GH concentration increased after feeding in pre-weaning goats although it did not change in post-weaning goats. It also suggests that an extensive change in ingested nutrients around the period of weaning induces an alteration in the regulation of hormone secretion. Before weaning, energy for ruminants depends on the nutrients that are derived from breast milk and taken up from the intestine like monogastric animals. However, after weaning, ruminants depend on the volatile fatty acids that are produced from fermentation of forages in the rumen. These changes in the digestive function could induce appropriate changes in the regulation of metabolism and hormone secretion.

Ghrelin levels are reported to increase before feeding but immediately recover to baseline levels after feeding is complete in sheep (Sugino et al., 2002). 
However, the present results show that plasma ghrelin levels do not change before and after feeding. This finding means that ghrelin secretion just before feeding may be lower in goats than in sheep.

CCK-8 administration partially mimicked the increase in GH level after feeding without changing the ghrelin level. It also suggests that weaning changes the GH response to CCK-8. This conclusion may be supported by the report that CCK receptor expression in several tissues changes during the period of weaning (Desbois et al., 1998; Yonekura et al., 2002).

\section{CONCLUSIONS}

In this study, the results indicate that a gastrointestinal hormone, CCK, can affect the somatotropic axis and mimic the post-prandial pattern of GH secretion in goats. This study also demonstrates that ghrelin is not involved in GH secretion after feeding. However, more detailed experiments are needed to elucidate the regulatory pathway of CCK on the somatotropic axis.

\section{REFERENCES}

Desbois C., Clerc P., Le H.I., Le D.G., Gestin M., Dufresne M., Fourmy D., Guilloteau P., 1998. Differential tissular expression of the CCK-A and CCK-B/Gastrin receptor genes during postnatal development in the calf. Life Sci. 63, 2059-2070

Gibbs J., Young R.C., Smith G.P., 1973. Cholecystokinin decrease food intake in rats. J. Comp. Physiol. Psychol. 84, 488

Kojima M., Hosoda H., Date Y., Nakazato M., Matsuo H., Kangawa K., 1999. Ghrelin is a growthhormone-releasing acylated peptide from stomach. Nature 402, 656-660

Moran T.H., Schwartz G.J., 1994. The neurobiology of cholecystokinin. Crit. Rev. Neurobiol. 9, 1

Murakami N., Hayashida T., Kuroiwa T., Nakahara K., Ida T., Mondal M. S., Nakazato M., Kojima M., Kangawa K., 2002. Role for central ghrelin in food intake and secretion profile of stomach ghrelin in rats. J. Endocrinol. 174, 283-288

Sugino T., Hasegawa Y., Kikkawa Y., Yamaura J., Yamagishi M., Kurose Y., Kojima M., Kangawa K., Terashima Y., 2002. A transient ghrelin surge occurs just before feeding in a scheduled mealfed sheep. Biochem. Biophys. Res. Commun. 295, 255-260

Toullec R., Chayvialle J.A., Guilloteau P., Bernard C., 1992. Early-life patterns of plasma gut regulatory peptide levels in calves. Effects of age, weaning and feeding. Comp. Biochem. Physiol. 102, 203-209

Yonekura S., Kitade K., Furukawa G., Takahashi K., Katsumata N., Katoh K., Obara Y., 2002. Effects of aging and weaning on mRNA expression of leptin and CCK receptors in the calf. Domest. Anim. Endocrinol. 22, 25-35 